\title{
Herdabilidade e correlações entre caracteres agronômicos em populações híbridas de trigo duro
}

\author{
Anita Martins Fontes Del Guercio $\left({ }^{1 *}\right)$; Carlos Eduardo de Oliveira Camargo $\left(^{2}\right)$ \\ (') Pós-Graduada de Mestrado em Agricultura Tropical, Área de Concentração de Genética, Melhoramento Vegetal e Biotecnologia \\ do Instituto Agronômico (IAC), Campinas (SP). Bolsista da FUNDAG. E-mail: animfdg@yahoo.com.br \\ (2) In memoriam.
}

Recebido: 2/fev./2009; Aceito: 22/abr./2010

\begin{abstract}
Resumo
Objetivou-se estimar os coeficientes de herdabilidade em sentido restrito referentes ao número de espigas por planta, de número de grãos por espiga, massa de cem grãos e produção de grãos, bem como as correlações ambientais, fenotípicas e genotípicas entre esses caracteres. Os estudos foram realizados em cruzamentos entre os genótipos de trigo duro P19 ( $\left.P_{1}\right)$ e P33 $\left(\mathrm{P}_{2}\right)$, ambos originados no programa do Instituto Agronômico (IAC), de Campinas e IAC-1003 $\left(\mathrm{P}_{3}\right)$, genótipo introduzido do Centro Internacional de Melhoramento de Milho e Trigo (CIMMYT), México. Baixas estimativas de herdabilidade no sentido restrito foram obtidas para o caráter número de espigas por planta $(0,23$ a 0,38$)$, exceto pelo cruzamento $P_{1} \times P_{2}(0,77)$. Valores baixos também foram obtidos para número de grãos por espiga $(0,13$ a 0,31$)$, excetuando-se o cruzamento $P_{1} \times P_{3}$ $(0,77)$. Para o caráter massa de cem grãos, os valores variaram de médios a baixos $(0,24$ a 0,49$)$ para todos os cruzamentos e também para produção de grãos $(0,09$ a 0,45$)$, sugerindo que a seleção para todos os caracteres na maioria dos cruzamentos deveria ser postergada para gerações posteriores. As correlações fenotípicas entre produção de grãos e os demais caracteres avaliados foram todas positivas e significativas, indicando que plantas com maior número de espigas, maior número de grãos por espiga e com grãos mais pesados seriam as mais produtivas.
\end{abstract}

Palavras-chave: Triticum durum L., componentes da produção, herdabilidade, correlação fenotípica, ambiental e genotípica.

\section{Heritability and correlations among agronomic characteristics in durum wheat hybrid populations}

\begin{abstract}
Narrow sense heritability values were estimated for number of spikes per plant, number of grains per spike, hundred kernel weight and grain yield, as well as environmental, phenotypic and genetic correlations among them. The studies were made for crosses among durum wheat genotypes P19 $\left(P_{1}\right)$ and P33 $\left(P_{2}\right)$, originated from the Instituto Agronômico de Campinas (IAC) breeding program, and IAC-1003 $\left(\mathrm{P}_{3}\right)$, genotype introduced from the International Improvement Center of Mayze and Wheat Breeding (CIMMYT), México. Low narrow sense heritabilities estimations were obtained for the character number of spikes per plant (0.23 to 0.38), except for the cross $P_{1} \times P_{2}(0.77)$. Low values also were obtained for number of grains per spike (0.13 to 0.31), except for the cross $P_{1} \times P_{3}(0.77)$. For the character hundred kernel weight, the values varied from medium to low (0.24 to 0.49) for all crosses and the same has occurred for grain yield (0.09 to 0.45), suggesting that the selection for all characters in most crosses should be done at last generations. Phenotypic correlations between grain yield and the other evaluated characters were all positive and significant indicating that plants with higher number of spikes, higher number of grains per spike and with heavier grains would be the highest yielding ones.
\end{abstract}

Key words: Triticum durum L., grain yield components, heritability, phenotypic, environmental and genetic correlation. 


\section{INTRODUÇÃO}

Os avanços na produção de grãos do trigo comum têm sido muito reportados na literatura (BRANCOURT-HuLMEL et al., 2003), contrastando com as referências ao trigo duro que ainda são bastante escassas (Royo et al., 2007). Historicamente, essa espécie tem recebido atenção insuficiente dos melhoristas (Sharma e SaIn, 2004).

A produção de grãos é um dos caracteres de relevante importância econômica, com herança complexa. O conhecimento das variâncias genéticas e fenotípicas bem como as associaçôes entre os componentes da produção de grãos e suas herdabilidades é de grande interesse para o desenvolvimento de estratégias de seleção adequadas (Kenga et al., 2006).

A produção de grãos depende da associação de muitos fatores genéticos e ambientais. Como resultado, o pesquisador de trigo se confronta com a dificuldade de escolha das linhas parentais, que, quando cruzadas, resultarão em maior proporção de segregantes desejáveis e, também, de selecionar as linhas superiores das progênies nas geraçóes segregantes finais. Além disso, somente pode ser utilizada parte da variabilidade genética total que resulta da ação aditiva de genes e das interaçôes de genes epistáticos que se comportam aditivamente, pois somente esses podem ser retidos nas geraçôes subsequentes de autofecundação (Kronstad e Foote, 1964).

A obtenção de cultivares envolve a seleção de vários caracteres simultaneamente. Logo, o conhecimento prévio de suas inter-relações também pode ser fundamental na estratégia a ser adotada pelo melhorista (Siqueira et al., 1993). A compreensão das variaçóes na produção, bem como de seus componentes e de caracteres associados ao longo do tempo, é também essencial para determinar os fatores limitantes da produção e apontar as futuras estratégias aos melhoristas (Royo et al., 2007).

O conhecimento da herdabilidade, no sentido restrito, é particularmente importante durante os trabalhos de seleção de plantas ou espigas visando à obtenção de novas cultivares, porque levam em consideração os efeitos aditivos de genes (Pepe e Heiner, 1975). De modo geral, as estimativas de herdabilidade determinam se os caracteres em estudo podem ou não ser aprimorados facilmente por meio do melhoramento genético (Fox et al., 2008).

De acordo com Falconer (1960), as correlaçôes nas quais foram utilizados dados de $\mathrm{F}_{1}$ são consideradas ambientais, aquelas usando dados de $\mathrm{F}_{2}$, fenotípicas, e as genotípicas são estimadas levando-se em consideração os valores das herdabilidades em sentido restrito e das correlaçóes fenotípicas e ambientais. Os princípios de genética quantitativa são utilizados para avaliar e comparar a eficiência da seleção direta e indireta. A seleção indireta seria a mais efetiva quando a correlação genética entre os dois caracteres fosse alta e positiva, e a herdabilidade do caráter secundário, fosse maior que a do caráter de interesse (DePAuw et al., 2007).
A partir de populaçôes híbridas de trigo duro provenientes de cruzamentos de três genótipos, o presente trabalho tem por objetivo estimar herdabilidades e correlaçôes, visando indicar como conduzir adequadamente as populaçôes segregantes para a obtenção de linhagens. Eventualmente, essas linhagens poderiam ser transformadas em novas cultivares de interesse para a triticultura do Estado de São Paulo.

\section{MATERIAL E MÉTODOS}

Para o presente trabalho foram realizados cruzamentos usando como parentais três genótipos de trigo duro: $\mathrm{P}_{1}$ (L19), $\mathrm{P}_{2}$ (L33) e $\mathrm{P}_{3}$ (IAC-1003).

Os genótipos utilizados foram escolhidos pelos grandes contrastes para os caracteres agronômicos como: número de espigas por planta, número de grãos por espiga, massa de cem grãos e produção de grãos.

L19 e L33 foram oriundas do programa de melhoramento do Instituto Agronômico (IAC) e IAC-1003 (Gallareta "S") foi introduzida do Centro Internacional de Melhoramento de Milho e Trigo (CIMMYT), México (CAMARgo et al., 1995a,b).

Foram obtidas as geraçôes $\mathrm{F}_{1}$ e $\mathrm{F}_{2}$ dos três cruzamentos, bem como os retrocruzamentos para ambos os parentais, $\mathrm{P}_{1}$ e $\mathrm{P}_{2}$, originando os $\mathrm{RC}_{1}$ e $\mathrm{RC}_{2}$ : $\left(\mathrm{P}_{1} \times \mathrm{P}_{2}\right) \times \mathrm{P}_{1},\left(\mathrm{P}_{1} \times \mathrm{P}_{3}\right) \times \mathrm{P}_{1}$, $\left(\mathrm{P}_{2} \times \mathrm{P}_{3}\right) \times \mathrm{P}_{2}$ e $\left(\mathrm{P}_{1} \times \mathrm{P}_{2}\right) \times \mathrm{P}_{2},\left(\mathrm{P}_{1} \times \mathrm{P}_{3}\right) \times \mathrm{P}_{3},\left(\mathrm{P}_{2} \times \mathrm{P}_{3}\right) \times \mathrm{P}_{3}$.

Os parentais $\left(\mathrm{P}_{1}, \mathrm{P}_{2}\right.$ e $\left.\mathrm{P}_{3}\right), \mathrm{F}_{1}$ 's, $\mathrm{F}_{2}$ 's, $\mathrm{RC}_{1}$ 's e $\mathrm{RC}_{2}$ 's foram germinados em laboratório e transplantados para vasos preenchidos com solo adubado e corrigido com calcário, de acordo com análises do solo, devidamente etiquetados, localizados em área telada em Campinas (SP). Foram plantadas três plântulas por vaso de cada genótipo.

O delineamento experimental foi em blocos ao acaso com 15 tratamentos, os quais incluíram os três parentais, os três $\mathrm{F}_{1}$ 's, os três $\mathrm{F}_{2}$ 's, os três $\mathrm{RC}_{1}$ 's e os três $\mathrm{RC}_{2}$ 's, com seis repetiçóes. A primeira e a segunda repetição foram instaladas em 12 de maio; a terceira e a quarta em 18 de maio; a quinta e a sexta 22 do mesmo mês. O conjunto das seis repetiçóes constituíu-se de 978 vasos.

As plantas mortas do ensaio foram substituídas por outras de trigo comum, da cultivar IAC-24, visando manter a competição entre as estudadas.

Foi plantada uma linha adicional de 162 vasos, com três plântulas da cultivar IAC-24, contornando o experimento, para minimizar os efeitos de bordadura.

Os dados coletados na base de plantas individuais foram os seguintes:

Número de espigas por planta - Computando o número total de espigas por planta.

Grãos por espiga - Número total de grãos da espiga do colmo principal.

Massa de cem gráos - Calculada a partir da massa, em grama, da amostra de grãos obtida em cada espiga. 
Produção de grãos - Massa, em grama, da produção total de grãos de cada planta.

As médias dos quatro caracteres agronômicos estudados foram submetidas à análise da variância (ANOVA), sendo o teste $\mathrm{F}$ utilizado para verificar a existência de variabilidade genética significativa. Os efeitos de geração na análise de variância foram divididos em componentes para detectar diferenças entre e dentro de geraçôes.

Os coeficientes de herdabilidade em sentido restrito foram estimados para todos os caracteres agronômicos estudados derivados de dados obtidos de plantas individuais nas geraçóes $\mathrm{F}_{2}$ 's, $\mathrm{RC}_{1}$ 's e $\mathrm{RC}_{2}$ 's, para cada um dos cruzamentos avaliados.

A estimativa da herdabilidade em sentido restrito $\mathrm{h}_{S \mathrm{R}}^{2}$ (proporção entre a variância genética aditiva e a fenotípica) foi calculada pelo método de Warner (1952), empregando a seguinte fórmula:

$\mathrm{h}_{\mathrm{SR}}^{2}=\left\{\left[2 \mathrm{VF}_{2}-\left(\mathrm{VRC}_{1}+\mathrm{VRC}_{2}\right)\right] / \mathrm{VF}_{2}\right\}$

Sendo:

$\mathrm{h}_{S \mathrm{R}}^{2}=$ herdabilidade em sentido restrito;

$\mathrm{VF}_{2}=$ variância do híbrido em geração $\mathrm{F}_{2}$;

$\mathrm{VRC}_{1}=$ variância do retrocruzamento 1 ;

$\mathrm{VRC}_{2}=$ variância do retrocruzamento 2 .

O erro-padráo para $\mathrm{h}_{S \mathrm{R}}^{2}$ foi obtido pela raiz quadrada da seguinte fórmula:

$\mathrm{V}\left(\mathrm{h}_{\mathrm{SR}}^{2}\right)=2\left\{\left[\left(\mathrm{VRC}_{1}+\mathrm{VRC}_{2}\right)^{2} / \mathrm{GLF}_{2}\right]+\left(\mathrm{V}^{2} \mathrm{RC}_{1} / \mathrm{GLRC}_{1}\right)\right.$ $\left.+\left(\mathrm{V}^{2} \mathrm{RC}_{2} / \mathrm{GLRC}_{2}\right)\right\} / \mathrm{V}^{2} \mathrm{~F}_{2}$

Sendo:

$\mathrm{V}\left(\mathrm{h}_{S \mathrm{R}}^{2}\right)=$ variância da herdabilidade em sentido restrito;

$\mathrm{VRC}_{1}=$ variância do retrocruzamento 1 ;

$\mathrm{VRC}_{2}=$ variância do retrocruzamento 2;

$\mathrm{VF}_{2}=$ variância do híbrido em geração $\mathrm{F}_{2}$;

$\mathrm{GLRC}_{1}$ = graus de liberdade associados com VRC ; $_{1}$

$\mathrm{GLRC}_{2}=$ graus de liberdade associados com $\mathrm{VRC}_{2}$;

$\mathrm{GLF}_{2}=$ graus de liberdade associados com $\mathrm{VF}_{2}$.

As correlaçôes fenotípicas, genotípicas e ambientais foram usadas para estimar o grau de associação entre os quatro caracteres agronômicos para cada uma das populações $\mathrm{P}_{1} \times \mathrm{P}_{2}, \mathrm{P}_{1} \times \mathrm{P}_{3}$ e $\mathrm{P}_{2} \times \mathrm{P}_{3}$.

Como sugere Falconer (1960), as correlaçóes usando dados das geraçôes $F_{1}$ 's são consideradas ambientais, aquelas com dados das geraçóes $\mathrm{F}_{2}$ 's, como fenotípicas, sendo as genotípicas estimadas por:

$r_{G}=\left[\left(r_{F}-\sqrt{ } E_{x} \sqrt{ } E_{y} r_{A}\right) / \sqrt{ } h^{2}{ }_{x} \sqrt{ } h_{y}^{2}\right]$

Sendo:

$\mathrm{r}_{\mathrm{G}}=$ coeficiente de correlação genotípica entre x e y;

$\mathrm{r}_{\mathrm{F}}=$ coeficiente de correlação fenotípica entre x e y;
$\mathrm{r}_{\mathrm{A}}=$ coeficiente de correlaçáo ambiental entre x e y;

$\mathrm{h}^{2}=$ estimativa da herdabilidade em sentido restrito, com subscrito x ou y, conforme o caráter.

$\mathrm{E}=1-\mathrm{h}^{2}$, também subscritos, de acordo com o caráter em estudo.

\section{RESULTADOS E DISCUSSÃO}

Verificou-se a existência de variabilidade genética significativa (Tabela 1) entre genótipos, entre geraçôes, dentro de geraçôes, entre pais, entre $\mathrm{F}_{2}$ 's e $\mathrm{RC}_{2}$ 's, considerando todos os caracteres avaliados. Entre os $\mathrm{F}_{1}$ 's verificou-se variabilidade genética para todos os caracteres, exceto produção de grãos; entre os $\mathrm{RC}_{1}$ 's só foi verificada variabilidade genética para as variáveis espigas por planta e grãos por espiga.

$\mathrm{O}$ parental $\mathrm{P}_{2}$ proporcionou os maiores números de espigas por planta, seguido de $\mathrm{P}_{1}$ e de $\mathrm{P}_{3}$.

Para o caráter número de grãos por espiga, o $\mathrm{P}_{3}$ destacou-se dos demais com os maiores valores. Na geraçáo $F_{1}$, os cruzamentos $\mathrm{P}_{1} \times \mathrm{P}_{2}$ e o $\mathrm{P}_{1} \times \mathrm{P}_{3}$ tiveram os maiores números de grãos por espiga.

Em relação à massa de cem grãos, o parental $\mathrm{P}_{3}$ também proporcionou grãos mais pesados, diferindo dos demais.

Os resultados apontaram que o $\mathrm{P}_{3}$ seria uma possível fonte de maior número de grãos por espiga bem como de maior massa de cem grãos, a ser usada em cruzamentos. Para produção de grãos o $\mathrm{P}_{3}$ foi destaque, novamente, diferindo dos demais.

As estimativas de herdabilidade em sentido restrito, para os quatro caracteres estudados, estão listadas na tabela 2. A herdabilidade em sentido restrito para o caráter número de espigas por planta foi baixa, exceto pelo cruzamento $P_{1} \times P_{2}$, com estimativa alta $(0,77)$. Valores baixos também foram observados para esse caráter por por VAN SAnford e Utomo (1995) em trigo comum.

Foram constados valores baixos para número de grãos por espiga, exceto pelo cruzamento $\mathrm{P}_{1} \times \mathrm{P}_{3}$ que teve valor elevado $(0,77)$.

Valores de médios a baixos foram estimados para massa de cem grãos para todos os cruzamentos, como analisado por Kenga et al. (2006) em sorgo e por VAN SANFord e Uтомо (1995) em trigo de inverno. Entretanto, as estimativas da herdabilidade em sentido amplo realizadas por Annicchiarico e Pecetti (1998), em trigo duro, foram altas, discordando do presente trabalho.

Em relação à produção de grãos, os valores estimados variaram de médios a baixos para os cruzamentos avaliados. Ketata et al. (1976) e Kenga et al. (2006) também observaram valores baixos de herdabilidade em sentido restrito para produção de grãos, em trigo comum e sorgo respectivamente. De forma semelhante, os valores de herdabilidade em sentido amplo estimados por ANNICCHIarico e PeCETТI (1998) foram medianos para a produção de grãos. 
Tabela 1. Resumo das análises de variância para os caracteres número de espigas por planta, número de grãos por espiga, massa de cem gráos e produçáo de grãos dos parentais, cruzamentos em geração $\mathrm{F}_{1}$ e $\mathrm{F}_{2}$, e dos $\mathrm{RC}_{1}$ e $\mathrm{RC}_{2}$ de trigo duro. Campinas, (2007)

\begin{tabular}{|c|c|c|c|c|c|}
\hline \multirow{2}{*}{ F.V. } & \multirow{2}{*}{ G.L. } & Espigas por planta & Grãos por espiga & Massa de cem grãos & Produção de grãos \\
\hline & & \multicolumn{2}{|c|}{ n. ${ }^{\circ}$} & \multicolumn{2}{|l|}{$\mathbf{g}$} \\
\hline Blocos & 5 & $2,41^{*}$ & 14,04 & 0,15 & $17,28^{*}$ \\
\hline Genótipos & 14 & $7,54^{*}$ & $392,18^{*}$ & $2,71^{*}$ & $34,44^{*}$ \\
\hline Entre gerações & 4 & $1,71^{*}$ & $393,78^{*}$ & $3,34^{*}$ & $44,56^{*}$ \\
\hline Dentro de gerações & 10 & $9,87^{*}$ & $391,54^{*}$ & $2,45^{*}$ & $30,39 *$ \\
\hline Pais & 2 & $23,09^{*}$ & $796,12^{*}$ & $6,26^{*}$ & $74,46^{*}$ \\
\hline $\mathrm{F}_{1} \mathrm{~s}$ & 2 & $3,01^{*}$ & $226,96^{*}$ & $2,53^{*}$ & 10,68 \\
\hline $\mathrm{F}_{2} \mathrm{~s}$ & 2 & $7,26^{*}$ & $400,28^{*}$ & $0,40^{*}$ & $15,08^{*}$ \\
\hline $\mathrm{RC}_{1} \mathrm{~s}$ & 2 & $5,91 *$ & $121,73^{*}$ & 0,05 & 0,45 \\
\hline $\mathrm{RC}_{2} \mathrm{~s}$ & 2 & $10,07^{*}$ & $412,60^{*}$ & $3,02^{*}$ & $51,30^{*}$ \\
\hline Pais $\mathrm{x}$ repetições & 10 & 0,42 & 10,59 & 0,04 & 0,58 \\
\hline $\mathrm{F}_{1} \mathrm{~s} \times$ repetições & 10 & 0,52 & 25,33 & 0,31 & 5,83 \\
\hline $\mathrm{F}_{2} \mathrm{~S} \times$ repetições & 10 & 0,27 & 11,91 & 0,02 & 1,33 \\
\hline $\mathrm{RC}_{1} \mathrm{~s} \times$ repetições & 10 & 0,51 & 6,35 & 0,04 & 2,37 \\
\hline $\mathrm{RC}_{2} \mathrm{~s} \times$ repetições & 10 & 0,80 & 11,55 & 0,05 & 2,59 \\
\hline Entre ger. $x$ repetições & 20 & 0,38 & 17,39 & 0,07 & 2,87 \\
\hline Dentro de ger. $\mathrm{x}$ repetições & 50 & 0,50 & 13,14 & 0,09 & 2,54 \\
\hline Genótipos x repetições & 70 & 0,47 & 14,36 & 0,08 & 2,63 \\
\hline Total & 89 & & & & \\
\hline
\end{tabular}

* Valores significativos ao nível de 5\%, pelo teste $\mathrm{F}$.

Tabela 2. Estimativas dos coeficientes de herdabilidade no sentido restrito para número de espigas por planta, número de grãos por espiga, massa de cem grãos e produçáo de grãos derivados de dados obtidos com base em plantas individuais dos parentais, $\mathrm{F}_{1} s, \mathrm{~F}_{2} \mathrm{~s}, \mathrm{RC}_{1} \mathrm{~s}$ e $\mathrm{RC}_{2}$ s para cada cruzamento envolvendo os genótipos de trigo duro $\mathrm{P}_{1}, \mathrm{P}_{2}$ e $\mathrm{P}_{3}$. Campinas, (2007)

$\begin{array}{lccc}\text { Caracteres } & \mathbf{P}_{\mathbf{1}} \mathbf{x} \mathbf{P}_{\mathbf{2}} & \mathbf{P}_{\mathbf{1}} \mathbf{x} \mathbf{P}_{\mathbf{3}} & \mathbf{P}_{\mathbf{2}} \mathbf{x} \mathbf{P}_{\mathbf{3}} \\ \left.\text { Número de espigas por planta (n. }{ }^{\circ}\right) & 0,77 \pm 0,13 & 0,38 \pm 0,17 & 0,23 \pm 0,19 \\ \text { Número de grãos por espiga }\left(\mathrm{n}^{\circ}\right) & 0,13 \pm 0,21 & 0,77 \pm 0,13 & 0,31 \pm 0,19 \\ \text { Massa de cem grãos (g) } & 0,49 \pm 0,16 & 0,36 \pm 0,18 & 0,24 \pm 0,19 \\ \text { Produção de grãos (g) } & 0,45 \pm 0,17 & 0,26 \pm 0,19 & 0,09 \pm 0,21\end{array}$

As correlaçôes fenotípicas entre produção de grãos e número de espigas por planta foram positivas e significativas para os três cruzamentos (Tabela 3), indicando que as plantas mais produtivas foram as que tiveram maior número de espigas por planta. Camargo (1989) e FerreiRA Filho et al. (2002), em cruzamentos de trigo comum, também estimaram correlação fenotípica entre produção de gráos e número de espigas por planta positiva e, igualmente significativa. As correlaçôes fenotípicas entre produção de grãos e massa de cem grãos também foram todas positivas e significativas, indicando que as plantas mais produtivas proporcionaram os grãos mais pesados. Para a correlação fenotípica entre produção de grãos e número de grãos por espiga, os valores dos três cruzamentos foram positivos e significativos. Gebeyehou et al. (1982) e Elhani et al. (2007) também analisaram resultados concordantes em trigo duro, com correlaçôes fenotípicas entre produção de grãos e número de grãos por espiga e, massa de grãos.

As correlaçōes entre número de grãos por espiga e massa de cem grãos foram negativas e significativas (Tabela 3 ) para os cruzamentos $\mathrm{P}_{1} \times \mathrm{P}_{3}$ e $\mathrm{P}_{2} \times \mathrm{P}_{3}$, e positiva e significativa para o cruzamento $P_{1} \times P_{2}$. Elhani et al. (2007) também verificaram em trigo duro correlaçóes positivas e significativas entre massa de mil grãos e número de grãos por espiga.
As correlaçóes entre número de espigas por planta e número de grãos por espiga e entre número de espigas por planta e massa de cem grãos foram significativas somente para o cruzamento $\mathrm{P}_{2} \times \mathrm{P}_{3}$, sendo negativa no primeiro caso e positiva, no segundo.

\section{CONCLUSÕES}

1. Estimativas de herdabilidade no sentido restrito são baixas, quando obtidas para o caráter número de espigas por planta e para número de grãos por espiga, exceto para os cruzamentos $\mathrm{P}_{1} \times \mathrm{P}_{2}$ e $\mathrm{P}_{1}$ x $\mathrm{P}_{3}$ respectivamente. Para os caracteres massa de cem grãos e produção de grãos, os valores variam de médio a baixo para todos os cruzamentos. Esse fato sugere que a seleção para todos os caracteres, na maioria dos cruzamentos, deveria ser postergada para geraçóes posteriores.

2. Os valores de correlação fenotípica obtidos entre produção de grãos e número de espigas por planta, número de grãos por espiga e massa de cem grãos apontam ser possível a seleçáo de plantas mais produtivas, em geraçóes posteriores, de maneira indireta. 
Tabela 3. Estimativas dos coeficientes de correlação ambiental $\left(\mathrm{r}_{\mathrm{A}}\right)$, fenotípica $\left(\mathrm{r}_{\mathrm{F}}\right)$ e genotípica $\left(\mathrm{r}_{\mathrm{G}}\right)$ entre os caracteres número de espigas por planta, número de gráos por espiga, massa de cem gráos e produção de grãos em ensaios provenientes do cruzamento entre os parentais de trigo duro $\mathrm{P}_{1}, \mathrm{P}_{2}$ e $\mathrm{P}_{3}$. Campinas, (2007)

\begin{tabular}{|c|c|c|c|}
\hline Cruzamentos & $\mathbf{r}_{\mathrm{A}}$ & $\mathbf{r}_{\mathbf{F}}$ & $\mathbf{r}_{G}$ \\
\hline \multicolumn{4}{|c|}{ Produção de grãos x número de espigas por planta } \\
\hline $\mathrm{P}_{1} \times \mathrm{P}_{2}$ & $0,64^{*}$ & $0,45^{*}$ & 0,17 \\
\hline$P_{1} \times P_{3}^{2}$ & $0,30^{*}$ & $0,62^{*}$ & 0,34 \\
\hline $\mathrm{P}_{2} \times \mathrm{P}_{3}$ & $0,75^{*}$ & $0,48^{*}$ & $-0,09$ \\
\hline \multicolumn{4}{|c|}{ Produção de grãos x número de grãos por espigas } \\
\hline $\mathrm{P}_{1} \times \mathrm{P}_{2}$ & $0,41^{*}$ & $0,65^{*}$ & 0,69 \\
\hline $\mathrm{P}_{1} \times \mathrm{P}_{3}$ & $0,66^{*}$ & $0,46^{*}$ & 0,11 \\
\hline $\mathrm{P}_{2} \times \mathrm{P}_{3}$ & $0,46^{*}$ & $0,51^{*}$ & 0,08 \\
\hline \multicolumn{4}{|c|}{ Produção de grãos $x$ massa de cem grãos } \\
\hline $\mathrm{P}_{1} \times \mathrm{P}_{2}$ & $-0,03$ & $0,26^{*}$ & 0,29 \\
\hline $\mathrm{P}_{1} \times \mathrm{P}_{3}$ & $0,72^{*}$ & $0,15^{*}$ & $-0,41$ \\
\hline$P_{2} \times P_{3}$ & 0,09 & $0,22^{*}$ & 0,24 \\
\hline \multicolumn{4}{|c|}{ Número de espigas por planta x número de grãos por espiga } \\
\hline$P_{1} \times P_{2}$ & 0,05 & 0,03 & 0,01 \\
\hline $\mathrm{P}_{1} \times \mathrm{P}_{3}$ & $-0,21^{*}$ & 0,03 & 0,08 \\
\hline$P_{2} \times P_{3}$ & $0,19^{*}$ & $-0,12^{*}$ & $-0,22$ \\
\hline \multicolumn{4}{|c|}{ Número de espigas por planta x massa de cem grãos } \\
\hline $\mathrm{P}_{1} \times \mathrm{P}_{2}$ & $-0,23^{*}$ & $-0,10$ & $-0,01$ \\
\hline $\mathrm{P}_{1} \times \mathrm{P}_{3}$ & $-0,06$ & $-0,05$ & $-0,01$ \\
\hline $\mathrm{P}_{2} \times \mathrm{P}_{3}$ & 0,06 & $0,11^{*}$ & 0,07 \\
\hline \multicolumn{4}{|c|}{ Número de grãos por espiga x massa de cem grãos } \\
\hline $\mathrm{P}_{1} \times \mathrm{P}_{2}$ & $-0,26^{*}$ & $0,11^{*}$ & 0,56 \\
\hline $\mathrm{P}_{1} \times \mathrm{P}_{3}$ & $0,67^{*}$ & $-0,17^{*}$ & $-0,29$ \\
\hline $\mathrm{P}_{2} \times \mathrm{P}_{3}$ & $0,25^{*}$ & $-0,15^{*}$ & $-0,29$ \\
\hline
\end{tabular}

\section{AGRADECIMENTO}

A autora agradece ao CNPq pelo financiamento parcial do trabalho e à Fundag pela concessão da bolsa de mestrado

\section{REFERÊNCIAS}

ANNICCHIARICO,P;;PECETTI,L.Yieldvs.morphophysiological trait-based criteria for selection of durum wheat in a semi-arid Mediterranean region (northern Syria). Field Crops Research, v.59, p.163-173, 1998.

BRANCOURT-HULMEL, M.; DOUSSINAULT, G.;LECOMTE, C.; BÉRARD, P.; LE BUANEC, B.; TROTTET, M. Genetic improvement of agronomic traits of winter wheat cultivars released in France from 1946 to 1992. Crop Science, v.43, p.37-45, 2003.

CAMARGO, C.E. de O. Melhoramento do trigo. XX. Herdabilidades e correlaçôes entre os componentes de produção em populaçóes híbridas envolvendo fontes de nanismo. Bragantia, v.48, p.39-52, 1989.

CAMARGO, C.E. de O.; FELICIO, J.C.; FERREIRA-FILHO, A.W.P.; GALLO, P.B.; PETTINELLI-JUNIOR, A.; SANTOS, R.R. dos; SABINO, J.C. Melhoramento do trigo. XXIX. Avaliação de linhagens da espécie de Triticum durum L. no Estado de São Paulo. Bragantia, v.54, p.67-79, 1995a.

CAMARGO, C.E. de O.; FELICIO, J.C.; SANTOS, R.R. dos; FERREIRA-FILHO, A.W.P. Trigo duro: comportamento de genótipos no Estado de São Paulo. Bragantia, v.54, p.305-317, 1995 b.
DePAUW, R.M.; KNOX, F.E.; CLARKE, F.R.; WANG, H.; FERNANDEZ, M.R.; CLARKE, J.M.; McCAIG, T.N. Shifting undesirable correlations. Euphytica, v.157, p.409-415, 2007.

ELHANI, S.; MARTOS, V.; RHARRABTI, Y.; ROYO, C.; GARCIA del MORAL, L.F. Contribution of main stem and tillers to durum wheat (Triticum turgidum L. var. durum) grain yield and its components grown in Mediterranean environments. Field Crops Research, v.103, p.25-35, 2007.

FALCONER, D.S. Introduction to quantitative genetics. New York: Ronald Press, 1960.365p.

FERREIRA FILHO, A.W.P.; CAMARGO, C.E. de O.; AYALAOSUNA, J. Heritability estimates and correlations between grain yield and other wheat agronomic characters. Científica, v.30, p.39$51,2002$.

FOX, G.P.; BOWMAN, J.; KELLY, A.; INKERMAN, A.; POULSEN, D.; HENRY, R. Assessing for genetic and environmental effects on ruminant feed quality in barley (Hordeum vulgare). Euphytica, v.163, p.249-257, 2008.

GEBEYEHOU, G.; KNOTT, D.R.; BAKER, R.J. Relationships among durations of vegetative and grain filling phases, yield components, and grain yield in durum wheat cultivars. Crop Science, v.22, p.287-290, 1982.

KENGA, R.; TENKOUANO, A.; GUPTA, S.C.; ALABI, S.O. Genetic and phenotypic association between yield components in hybrid sorghum (sorghum bicolor (L.) Moench) populations. Euphytica, v.150, p.319-326, 2006. 
KETATA, H.; EDWARDS, L.H.; SMITH, E.L. Inheritance of eight agronomic characters in a winter wheat cross. Crop Science, v.16, p.19-22, 1976.

KRONSTAD, W.E.; FOOTE, W.H. General and specific combining ability estimates in winter wheat (Triticum aestivum Vill., Hot). Crop Science, v.4, p.616-619, 1964.

PEPE, J.F.; HEINER, R.E. Plant height protein percentage and yield relationship in spring wheat. Crop Science, v.15, p.793-797, 1975.

ROYO, C.; ÁLVARO, F.; MARTOS, V.; RAMDANI, A.; ISIDRO, J.; VILLEGAS, D.; GARCIA del MORAL, L.F. Genetic changes in durum wheat yield components and associated traits in Italian and Spanish varieties during the $20^{\text {th }}$ century. Euphytica, v.155, p.259-270, 2007.

SHARMA, S.N.; SAIN, R.S. Genetics of grains per spike in durum wheat under normal and late planting conditions. Euphytica, v.139, p.1-7, 2004.

SIQUEIRA, W.J.; ILLG, R.D.;FORNASIER, J.B.; GRANJA, N.P.; LISBÃO, R.S.; SANTOS, R.R. Correlações fenotípica, genética aditiva e ambiental em cenoura. Bragantia, v.52, p.17-26, 1993.

VAN SANFORD, D.A.; UTOMO, H. Inheritance of tillering in a winter wheat population. Crop Science, v.35, p.1566-1569, 1995. 